\title{
Association study of stuttering candidate genes GNPTAB, GNPTG and NAGPA with dyslexia in Chinese population
}

Huan Chen ${ }^{1 \dagger}$, Junquan Xu ${ }^{2,3+}$, Yuxi Zhou ${ }^{2,3}$, Yong Gao ${ }^{2,3}$, Guoqing Wang ${ }^{2,3}$, Jiguang Xia ${ }^{2,3}$, Michael SY Huen ${ }^{4}$, Wai Ting Siok ${ }^{5,6}$, Yuyang Jiang ${ }^{7}$, Li Hai Tan ${ }^{8,9^{*}}$ and Yimin Sun ${ }^{2,3,7,10^{*}}$

\begin{abstract}
Background: Dyslexia is a polygenic speech and language disorder characterized by an unexpected difficulty in reading in children and adults despite normal intelligence and schooling. Increasing evidence reveals that different speech and language disorders could share common genetic factors. As previous study reported association of GNPTAB, GNPTG and NAGPA with stuttering, we investigated these genes with dyslexia through association analysis.

Results: The study was carried out in an unrelated Chinese cohort with 502 dyslexic individuals and 522 healthy controls. In all, 21 Tag SNPs covering GNPTAB, GNPTG and NAGPA were subjected to genotyping. Association analysis was performed on all SNPs. Significant association of rs17031962 in GNPTAB and rs882294 in NAGPA with developmental dyslexia was identified after FDR correction for multiple comparisons.
\end{abstract}

Conclusion: Our results revealed that the stuttering risk genes GNPTAB and NAGPA might also associate with developmental dyslexia in the Chinese population.

Keywords: Developmental dyslexia, GNPTAB, GNPTG, NAGPA, SNPs

\section{Background}

Speech and language disorders can be classified into numerous categories, including stuttering, speech sound disorder (SSD), verbal dyspraxia, specific language impairment (SLI) and developmental dyslexia (DD) [1]. Dyslexia, also known as reading disability (RD), is characterized by difficulties in reading and spelling despite of normal intelligence and adequate education background without any neurological impairments [2,3]. Though language disorders such as dyslexia are quite different concept from speech disorders, in many cases, it is difficult to discriminate a language disorder from a speech disorder in a specific individual [4]. Hence, some researchers regard them as a continuum of language disorders [5-7]. Motor deficiency might be one of the

\footnotetext{
* Correspondence: lihaitan@gmail.com; ymsun@capitalbio.com

${ }^{\dagger}$ Equal contributors

${ }^{8}$ Neuroimaging Laboratory, Department of Biomedical Engineering, School of Medicine, Shenzhen University, Shenzhen, China

${ }^{2}$ National Engineering Research Center for Beijing Biochip Technology,

Beijing 102206, China

Full list of author information is available at the end of the article
}

underlying mechanisms that explain how the two defects are connected. For instance, stuttering has been attributed to a temporal motor defect in speech preparation $[8,9]$. In terms of dyslexia, some recent studies have revealed that dyslexic individuals suffer from motor problems as well, especially in performing fine movements $[6,10]$. A great deal of evidence reveals that language disorders and speech disorders could share some genetic factors. For example, forkhead box P2 (FOXP2) and its downstream target gene contactin associated proteinlike 2 (CNTNAP2) have been shown to be an important link in the networks of several speech and language disorders, including SLI, dyslexia, stuttering and dyspraxia [1,11-20]. This viewpoint triggered us to verify whether candidate genes for stuttering were also involved in the pathogenesis of developmental dyslexia.

Recently, in a study of stuttering individuals from Pakistan and North America, candidate gene and linkage analyses identified several mutations in the lysosomal enzymetargeting pathway genes N-acetylglucosamine-1-phosphate transferase gene (GNPTAB), N-acetylglucosamine- 
1-phosphate transferase, gamma subunit (GNPTG) and $\mathrm{N}$-acetylglucosamine-1-phosphodiester alpha- $\mathrm{N}$-acetylglucosaminidase (NAGPA) [21]. Subsequent studies of stuttering identified mutations in the GNPTAB gene and two functionally related GNPTG and NAGPA genes in large families and in the sporadic patients, reaffirming their association with stuttering [22-24]. However, the relevance of these genes with dyslexia has not yet been reported. It has been shown that stuttering is more common in children who suffer from concomitant speech, language, or motor deficiencies, implying that speech and language disorders may be connected genetically to some extent. Therefore, the three genes (GNPTAB, GNPTG and NAGPA) that may predispose people to stuttering are potential candidate risk genes for other speech and language disorders. Based on the above evidence, we performed association analysis on these genes with dyslexia in a large unrelated Chinese cohort.

\section{Results}

Single marker analysis

In the present study, we performed genotyping on Tag SNPs of three candidate genes for stuttering, GNPTAB, GNPTG and NAGPA. Data adjustment for age and sex was performed on genotyping results. Table 1 shows the SNP markers with significant unadjusted p-values $(<0.05)$ in the study.

In GNPTAB, we genotyped 11 Tag SNPs and found nominal association of one SNP with dyslexia before adjustment (Additional file 1). SNP rs10778148 showed significant association with dyslexia under recessive model $(\mathrm{P}=0.007633, \mathrm{OR}=7.568)$ and in homozygous genotype $(\mathrm{P}=0.008803$, $\mathrm{OR}=7.3083)$. After the adjustment for age and sex, the association between SNP rs10778148 and dyslexia remained significant under recessive model $(\mathrm{P}=0.01205$, $\mathrm{OR}=7.462)$ and in homozygous genotype $(\mathrm{P}=0.01364$, $\mathrm{OR}=7.2499)$. Moreover, we found rs17031962 achieved significant level under dominant model $\left(\mathrm{P}_{\text {adjusted }}=0.003443, \mathrm{OR}=0.6647\right)$ and in heterozygous genotype $\left(\mathrm{P}_{\text {adjusted }}=0.007001, \mathrm{OR}=\right.$ 0.6738) after adjustment for age and sex. However, only the P-value of rs17031962 under dominant model $\left(P_{\text {adjusted }}=0.0357\right)$ remained significant after the FDR adjustment for multiple comparisons.

In GNPTG, we genotyped 2 Tag SNPs (Additional file 2) and only found one SNP significantly associated with dyslexia before adjustment. SNP rs2887538 showed significantly associated with dyslexia under dominant model $(\mathrm{P}=0.03411, \mathrm{OR}=0.7634)$. However, no significant association was found after FDR correction.

In NAGPA, we genotyped 8 Tag SNPs (Additional file 3) and only found one SNP significantly associated with dyslexia before adjustment. SNP rs882294 showed significantly associated with dyslexia under additive model $(\mathrm{P}=0.006043$, $\mathrm{OR}=1.404)$, dominant model $(\mathrm{P}=0.006426$, $\mathrm{OR}=1.462)$ and in heterozygous genotype $(\mathrm{P}=0.01175$, $\mathrm{OR}=1.4361$ ). After the adjustment for age and sex, the association between SNP rs882294 and dyslexia remained significant under additive model $\left(\mathrm{P}_{\text {adjusted }}=\right.$ $0.001571, \mathrm{OR}=1.531)$, dominant model $\left(\mathrm{P}_{\text {adjusted }}=\right.$ $0.00167, \mathrm{OR}=1.611$ ) and in heterozygous genotype $\left(\mathrm{P}_{\text {adjusted }}=0.003546, \mathrm{OR}=1.6765\right)$. While after FDR correction, the association between SNP rs882294 and dyslexia remained significant under additive model $\left(\mathrm{P}_{\text {adjusted }}=0.0336\right)$ and dominant model $\left(\mathrm{P}_{\text {adjusted }}=\right.$ 0.0357).

\section{Haplotype analysis}

We built 3 blocks within GNPTAB and 3 blocks within $N A G P A$ through Haploview software (Figures 1 and 2).

In GNPTAB, haplotype analysis was conducted in three blocks (Table 2). All blocks were not associated with dyslexia ( $\mathrm{P}>0.05$ Omnibus test), but a four marker protective haplotype TTCT (Block1 rs1811338-rs1703 1962-rs10778148-rs11111007) was identified after adjustment for age and sex $\left(\mathrm{P}_{\text {adjusted }}=0.00985\right.$, OR $=$ 0.761). However, all $\mathrm{P}$-values failed to reach significance after the FDR correction.

In NAGPA, haplotype analysis was conducted in three blocks (Table 3). Block 3 consisting of rs1001170, rs882294 and rs17137545 was associated with dyslexia $(\mathrm{P}=0.0228$ Omnibus test $)$, and included one risk haplotype TCT $\left(\mathrm{P}_{\text {unadjusted }}=0.0129, \mathrm{OR}=1.38\right)$. After adjustment for age and sex, the association for haplotype TCT in Block 1 remain significant $\left(\mathrm{P}_{\text {adjusted }}=0.00289, \mathrm{OR}=\right.$ 1.52), and a risk haplotype GTC in Block 2 (rs12929808rs7110-rs3743840) achieved significant level $\left(\mathrm{P}_{\text {adjusted }}=\right.$ 0.0494, OR $=1.28$ ). However, all $\mathrm{P}$-values failed to reach significance after the FDR correction.

\section{Discussion}

Generally, deficits in speech and language functions can be characterized as expressive (production), as receptive (comprehension) or as mixed [4]. Genetically, different mental disorders may share some common factors [1,11-20]. The present study aimed to identify the correlation between dyslexia and three stuttering associated genes, GNPTAB, GNPTG, and NAGPA. Our data showed that genetic variants of GNPTAB and NAGPA might contribute to the pathogenesis of dyslexia.

GNPTAB and GNPTG genes encode the alpha and beta subunits and gamma subunit of enzyme UDPGlcNAc-1-phosphotransferase (GNPT), which is essential to proper trafficking of lysosomal acid hydrolases [25]. Mutations in GNPTAB and GNPTG genes could cause mucolipidosis types II and III, which are severe forms of autosomal recessive lysosomal storage diseases 
Table 1 Association between significant SNP markers and dyslexia using the additive, dominant, genotype, and the recessive models

\begin{tabular}{|c|c|c|c|c|c|c|c|c|}
\hline Gene & SNP & Patient & Control & $\begin{array}{l}\text { Crude OR } \\
(95 \% \mathrm{Cl}) \\
\end{array}$ & $\begin{array}{l}\text { Unadjusted } \\
\text { p-value }\end{array}$ & $\begin{array}{l}\text { Adjusted OR } \\
(95 \% \mathrm{Cl})\end{array}$ & $\begin{array}{l}\text { Adjusted } \\
\text { p-value }\end{array}$ & $\begin{array}{l}\text { FDR corrected } \\
\text { p-value }\end{array}$ \\
\hline \multirow[t]{26}{*}{ GNPTAB } & rs17031962 & & & & & & & \\
\hline & C Allele & 677 & 678 & 1.000 & & 1.000 & & \\
\hline & T Allele & 287 & 340 & 0.844 & 0.082 & 0.748 & 0.006 & 0.065 \\
\hline & & & & $(0.6977-1.022)$ & & $(0.6079-0.9209)$ & & \\
\hline & $\mathrm{CC}$ & 240 & 222 & 1.000 & & 1.000 & & \\
\hline & CT & 197 & 234 & 0.779 & 0.062 & 0.674 & 0.007 & 0.074 \\
\hline & & & & $(0.5986-1.0131)$ & & $(0.5057-0.8977)$ & & \\
\hline & $\pi$ & 45 & 53 & 0.785 & 0.279 & 0.672 & 0.093 & 0.326 \\
\hline & & & & $(0.5072-1.2161)$ & & $(0.4226-1.0687)$ & & \\
\hline & Dom & & & 0.780 & 0.052 & 0.665 & 0.003 & 0.036 \\
\hline & & & & $(0.6074-1.002)$ & & $(0.5056-0.8739)$ & & \\
\hline & $\operatorname{Rec}$ & & & 0.886 & 0.571 & 0.771 & 0.255 & 0.596 \\
\hline & & & & $(0.5831-1.346)$ & & $(0.4917-1.207)$ & & \\
\hline & rs10778148 & & & & & & & \\
\hline & C Allele & 854 & 909 & 1.000 & & 1.000 & & \\
\hline & T Allele & 110 & 107 & 1.090 & 0.540 & 1.148 & 0.368 & 0.639 \\
\hline & & & & $(0.827-1.437)$ & & $(0.8501-1.55)$ & & \\
\hline & $\mathrm{CC}$ & 386 & 403 & 1.000 & & 1.000 & & \\
\hline & CT & 82 & 103 & 0.831 & 0.260 & 0.899 & 0.547 & 0.976 \\
\hline & & & & $(0.6024-1.1468)$ & & $(0.6350-1.2722)$ & & \\
\hline & $\pi$ & 14 & 2 & 7.308 & 0.009 & 7.250 & 0.014 & 0.286 \\
\hline & & & & $(1.6501-32.3685)$ & & $(1.5021-34.9920)$ & & \\
\hline & Dom & & & 0.955 & 0.769 & 1.022 & 0.897 & 0.966 \\
\hline & & & & $(0.7001-1.301)$ & & $(0.731-1.43)$ & & \\
\hline & $\operatorname{Rec}$ & & & 7.568 & 0.008 & 7.462 & 0.012 & 0.254 \\
\hline & & & & $(1.711-33.48)$ & & $(1.554-35.83)$ & & \\
\hline \multirow[t]{13}{*}{ GNPTG } & rs2887538 & & & & & & & \\
\hline & G Allele & 713 & 709 & 1.000 & & 1.000 & & \\
\hline & A Allele & 253 & 309 & 0.814 & 0.040 & 0.850 & 0.132 & 0.401 \\
\hline & & & & $(0.6689-0.9909)$ & & $(0.6879-1.05)$ & & \\
\hline & GG & 265 & 245 & 1.000 & & 1.000 & & \\
\hline & $A G$ & 183 & 219 & 0.773 & 0.054 & 0.829 & 0.195 & 0.775 \\
\hline & & & & $(0.5944-1.0041)$ & & $(0.6243-1.1006)$ & & \\
\hline & $\mathrm{AA}$ & 35 & 45 & 0.719 & 0.173 & 0.754 & 0.275 & 0.481 \\
\hline & & & & $(0.4473-1.1559)$ & & $(0.4533-1.2525)$ & & \\
\hline & Dom & & & 0.763 & 0.034 & 0.815 & 0.138 & 0.454 \\
\hline & & & & $(0.5947-0.98)$ & & (0.6225-1.068) & & \\
\hline & $\operatorname{Rec}$ & & & 0.806 & 0.357 & 0.816 & 0.421 & 0.695 \\
\hline & & & & $(0.5083-1.277)$ & & $(0.4968-1.34)$ & & \\
\hline \multirow[t]{4}{*}{ NAGPA } & rs882294 & & & & & & & \\
\hline & T Allele & 785 & 877 & 1.000 & & 1.000 & & \\
\hline & C Allele & 179 & 143 & 1.404 & 0.006 & 1.531 & 0.002 & 0.034 \\
\hline & & & & $(1.102-1.789)$ & & $(1.176-1.994)$ & & \\
\hline
\end{tabular}


Table 1 Association between significant SNP markers and dyslexia using the additive, dominant, genotype, and the recessive models (Continued)

\begin{tabular}{|c|c|c|c|c|c|c|c|}
\hline$\pi$ & 318 & 377 & 1.000 & & 1.000 & & \\
\hline \multirow[t]{2}{*}{$\mathrm{CT}$} & 149 & 123 & 1.436 & 0.012 & 1.577 & 0.004 & 0.074 \\
\hline & & & $(1.0837-1.9032)$ & & $(1.1609-2.1408)$ & & \\
\hline \multirow[t]{2}{*}{ CC } & 15 & 10 & 1.778 & 0.166 & 2.060 & 0.112 & 0.337 \\
\hline & & & $(0.7880-4.0131)$ & & $(0.8443-5.0280)$ & & \\
\hline \multirow[t]{2}{*}{ Dom } & & & 1.462 & 0.006 & 1.611 & 0.002 & 0.036 \\
\hline & & & $(1.113-1.921)$ & & $(1.197-2.169)$ & & \\
\hline \multirow[t]{2}{*}{$\operatorname{Rec}$} & & & 1.606 & 0.252 & 1.793 & 0.195 & 0.560 \\
\hline & & & $(0.7144-3.61)$ & & $(0.742-4.333)$ & & \\
\hline
\end{tabular}

[26,27]. Here we identified that two SNP markers, rs17031962 and rs10778148, were associated with dyslexia with significant adjusted p-value. However, only an intronic SNP marker rs17031962 was associated with dyslexia under dominant model after the FDR correction.

Moreover, NAGPA encodes a Golgi enzyme that catalyzes the second step in the formation of the mannose 6-phosphate recognition marker on lysosomal hydrolases [28]. Our data showed that SNP rs882294 was associated with dyslexia with the allele $\mathrm{C}$ as a risk factor after FDR correction. Recently, three mutations in the NAGPA gene including one deletion and two missenses have been identified in patients with persistent stuttering. Further biochemical analysis shows that these mutations could impair folding and change degradation activity by the proteasomal system [29]. Since both GNPTAB and NAGPA are involved in lysosomal decomposition, the above evidence may reveal a potential role for inherited enzyme deficiencies in lysosomal metabolism in speech and language disorders such as stuttering and dyslexia. Furthermore, this knowledge may trigger a variety of new investigations that could help to explore the biological mechanism underlying speech and language disorders.

\section{Conclusion}

In conclusion, we found significant association between development dyslexia and genetic variants in genes encoding the lysosomal targeting system in a large unrelated Chinese cohort. Our data also supported that there are common genetic factors underlying the pathophysiology of different speech and language disorders.

\section{Methods}

\section{Subjects}

Dyslexia screening underwent the two-stage procedures as previously reported. The criteria for dyslexic patients

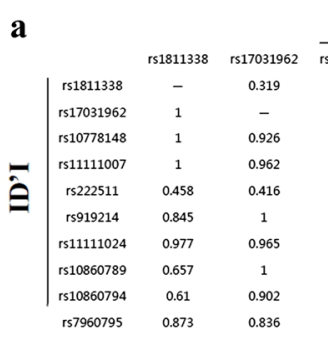

\begin{tabular}{|c|c|c|c|c|}
\hline & & $\mathrm{r}^{2}$ & & \\
\hline rs 10778148 & rs111111007 & rs222511 & rs919214 & rs111111024 \\
\hline 0.074 & 0.135 & 0.045 & 0.391 & 0.598 \\
\hline 0.051 & 0.099 & 0.03 & 0.174 & 0.472 \\
\hline- & 0.025 & 0.022 & 0 & 0.109 \\
\hline 1 & - & 0.423 & 0.074 & 0.157 \\
\hline 0.745 & 0.823 & - & 0.066 & 0.072 \\
\hline 0.084 & 1 & 0.751 & - & 0.343 \\
\hline 0.969 & 0.855 & 0.457 & 1 & - \\
\hline 0.124 & 1 & 1 & 1 & 1 \\
\hline 0.562 & 0.947 & 0.49 & 0.364 & 0.922 \\
\hline 1 & 1 & 0.55 & 0.426 & 0.862 \\
\hline
\end{tabular}

$\begin{array}{ccc}r 510860789 & \mathrm{rs} 10860794 & \mathrm{r} 57960795 \\ 0.087 & 0.36 & 0.415 \\ 0.064 & 0.249 & 0.121 \\ 0.014 & 0.061 & 0.04 \\ 0.027 & 0.117 & 0.073 \\ 0.043 & 0.05 & 0.036 \\ 0.368 & 0.075 & 0.181 \\ 0.126 & 0.515 & 0.253 \\ - & 0.077 & 0.044 \\ 1 & - & 0.541\end{array}$

b

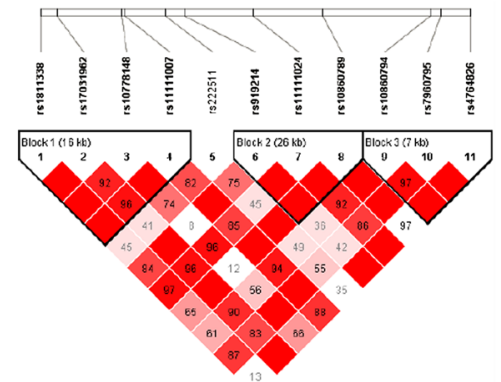

Figure 1 Linkage disequilibrium analysis of the 11 SNPs in GNPTAB investigated in healthy controls (a). Three blocks were identified using Haploviewsoftware (b). 


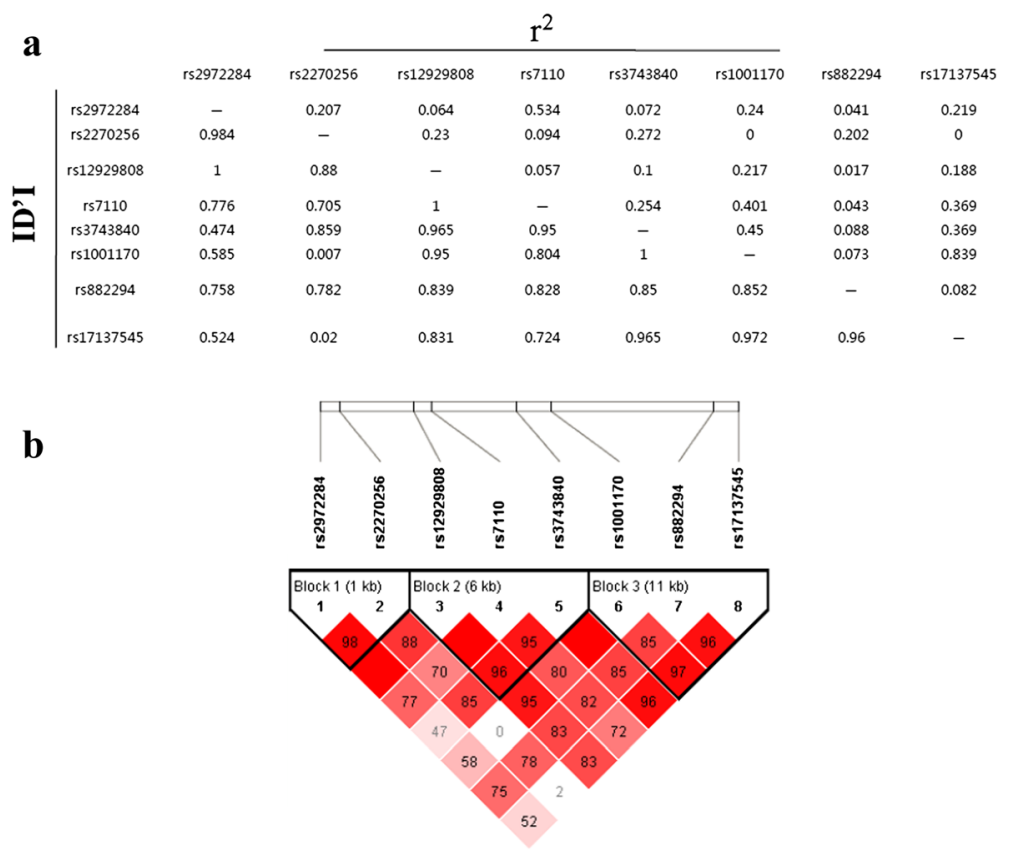

Figure 2 Linkage disequilibrium analysis of the 8 SNPs in NAGPA investigated in healthy controls (a). Three blocks were identified using Haploviewsoftware (b).

and healthy individuals was described previously [30]. This study was approved by the ethical committee of Tsinghua University School of Medicine. The guardians of children under 16 gave informed, written consent about participation in the study. Briefly, 6,900 primary school students aged between 7 to 13 from Shandong province of China were subjected to a Chinese reading test consisting of character-, word-, and sentence-level questions. Then, 1794 participants whose reading scores were above 87th percentile or below the 13th percentile among all students in the same grade were chosen for further evaluation. These participants were subjected to a character reading test composed of 300 Chinese characters individually for the assessment of reading ability. Then the Raven's Standard Test was performed to exclude individuals with intelligent deficiency. In total, 1024 children were selected for subsequent analysis, including 502 dyslexic patients and 522 controls.

Table 2 Haplotypes of the three blocks in GNPTAB between developmental dyslexia and control subjects

\begin{tabular}{|c|c|c|c|c|c|c|c|}
\hline \multirow[t]{2}{*}{ Haplotype } & \multicolumn{2}{|c|}{ Haplotype frequency } & \multirow[t]{2}{*}{ OR } & \multirow[t]{2}{*}{$\mathbf{P}_{\text {unadjusted }}$} & \multirow[t]{2}{*}{ OR } & \multirow[t]{2}{*}{$\mathrm{P}_{\text {adjusted }}$} & \multirow[t]{2}{*}{$P_{\mathrm{FDR}}$} \\
\hline & Patient & Control & & & & & \\
\hline OMNIBUS & & & NA & 0.354 & NA & 0.078 & 0.204 \\
\hline TCCC & 0.169 & 0.174 & 0.965 & 0.764 & 1.060 & 0.660 & \\
\hline TCTT & 0.113 & 0.104 & 1.090 & 0.541 & 1.150 & 0.372 & \\
\hline TTCT & 0.297 & 0.331 & 0.853 & 0.103 & 0.761 & 0.010 & \\
\hline GCCT & 0.418 & 0.388 & 1.130 & 0.178 & 1.160 & 0.128 & \\
\hline OMNIBUS & & & NA & 0.194 & NA & 0.166 & 0.212 \\
\hline TCT & 0.102 & 0.113 & 0.888 & 0.415 & 0.932 & 0.651 & \\
\hline CAC & 0.463 & 0.497 & 0.880 & 0.152 & 0.831 & 0.055 & \\
\hline TCC & 0.177 & 0.144 & 1.260 & 0.056 & 1.240 & 0.108 & \\
\hline CCC & 0.258 & 0.246 & 1.050 & 0.617 & 1.130 & 0.276 & \\
\hline OMNIBUS & & & NA & 0.190 & NA & 0.177 & 0.212 \\
\hline CCG & 0.134 & 0.125 & 1.080 & 0.558 & 1.180 & 0.249 & \\
\hline CTC & 0.286 & 0.254 & 1.170 & 0.120 & 1.150 & 0.197 & \\
\hline ACC & 0.577 & 0.619 & 0.850 & 0.074 & 0.833 & 0.063 & \\
\hline
\end{tabular}


Table 3 Haplotypes of the three blocks in NAGPA between developmental dyslexia and control subjects

\begin{tabular}{|c|c|c|c|c|c|c|c|}
\hline \multirow[t]{2}{*}{ Haplotype } & \multicolumn{2}{|c|}{ Haplotype frequency } & \multirow[t]{2}{*}{ OR } & \multirow[t]{2}{*}{$\mathrm{P}_{\text {unadjusted }}$} & \multirow[t]{2}{*}{ OR } & \multirow[t]{2}{*}{$\mathrm{P}_{\text {adjusted }}$} & \multirow[t]{2}{*}{$P_{\mathrm{FDR}}$} \\
\hline & Patient & Control & & & & & \\
\hline \multicolumn{8}{|c|}{ Block1 rs2972284-rs2270256 } \\
\hline OMNIBUS & & & NA & 0.494 & NA & 0.467 & 0.467 \\
\hline CC & 0.333 & 0.328 & 1.030 & 0.770 & 1.060 & 0.572 & \\
\hline$\pi$ & 0.322 & 0.302 & 1.090 & 0.381 & 1.080 & 0.470 & \\
\hline$C T$ & 0.344 & 0.369 & 0.896 & 0.253 & 0.880 & 0.218 & \\
\hline \multicolumn{8}{|c|}{ Block2 rs12929808-rs7110-rs3743840 } \\
\hline OMNIBUS & & & NA & 0.203 & NA & 0.102 & 0.204 \\
\hline GTT & 0.388 & 0.411 & 0.900 & 0.263 & 0.881 & 0.210 & \\
\hline GCC & 0.280 & 0.267 & 1.070 & 0.511 & 1.080 & 0.493 & \\
\hline ATC & 0.108 & 0.125 & 0.840 & 0.217 & 0.787 & 0.117 & \\
\hline GTC & 0.212 & 0.183 & 1.220 & 0.090 & 1.280 & 0.049 & \\
\hline \multicolumn{8}{|c|}{ Block3 rs1001170-rs882294-rs17137545 } \\
\hline OMNIBUS & & & NA & 0.078 & NA & 0.023 & 0.137 \\
\hline GTC & 0.337 & 0.345 & 0.965 & 0.709 & 0.954 & 0.648 & \\
\hline TCT & 0.170 & 0.131 & 1.380 & 0.013 & 1.520 & 0.003 & \\
\hline GTT & 0.026 & 0.027 & 0.979 & 0.941 & 0.896 & 0.722 & \\
\hline ताT & 0.445 & 0.482 & 0.859 & 0.094 & 0.831 & 0.061 & \\
\hline
\end{tabular}

\section{SNP markers selection and genotyping}

In total, 21 Tag SNPs covering GNPTAB, GNPTG and NAGPA were selected through Tagger program [31] with parameters of minor allele frequency (MAF) over 5\% and pairwise $r^{2}$ threshold of 0.8 . The SNP genotyping was performed on SequenomMassARRAY platform (Sequenom, San Diego, CA) at CapitalBio Corporation (Beijing, China). Genomic DNA samples were extracted from saliva samples using Oragene ${ }^{\mathrm{TM}}$ DNA self-collection kit (DNA Genotek Inc., Ottawa, Ontario, Canada) and DNA quantity was determined by Nanodrop spectrophotometry (Nanodrop 1000 Spectrophotometer, Thermo Scientific, Wilmington, DE). A locus-specific PCR reaction based on a locus-specific primer extension reaction was designed using the MassARRAY Assay Design software package (v3.1). MALDI-TOF mass spectrometer and Mass ARRAY Type 4.0 software were used for mass determination and data acquisition.

\section{Data analysis}

Statistical analysis was undertaken using PLINK software (http://pngu.mgh.harvard.edu/ purcell/plink/), which is an open-source whole genome association analysis toolset and is commonly used to perform a range of basic, large-scale analyses [32]. Hardy-Weinberg equilibrium (HWE) tests were undertaken for each SNP, and association tests were performed using additive, dominant, or recessive genetic models. Haplotype analyses were performed using Haploview software (Version 4.2). Haploview is a software package that provides computation of linkage disequilibrium (LD) in genetic data, performs association studies, chooses tagSNPs and estimates haplotype frequencies $[33,34]$. Chi square tests were used to test for haplotype association and full model association (Genotype, Dom, Rec). A Fisher's exact test was used for allelic association. Logistic regression was applied for risk stratification with or without covariate (age and sex) in both single marker and haplotype analysis. False discovery rate (FDR) correction for multiple testing was undertaken for the 21 SNPs that were adopted into the single site association analysis.

\section{Additional files}

Additional file 1: Table S1. Association between SNPs in GNPTAB and dyslexia using the additive, dominant, genotype, and the recessive models. Additional file 2: Table S2. Association between SNPs in GNPTG and dyslexia using the additive, dominant, genotype, and the recessive models.

Additional file 3: Table S3. Association between SNPS in NAGPA and dyslexia using the additive, dominant, genotype, and the recessive models.

\section{Abbreviations}

SSD: Speech sound disorder; SLI: Specific language impairment; DD: Developmental dyslexia; RD: Reading disability; GNPTAB: Nacetylglucosamine-1-phosphate transferase gene; GNPTG: Nacetylglucosamine-1-phosphate transferase, gamma subunit; NAGPA: Nacetylglucosamine-1-phosphodiester alpha-N-acetylglucosaminidase; FDR: False discovery rate; MAF: Minor allele frequency; HWE: Hardy-Weinberg equilibrium; LD: Linkage disequilibrium.

\section{Competing interests}

The authors declare that they have no competing interests. 


\section{Authors' contributions}

YS and LT conceived and designed the experiments; HC, JX, GW and JX performed the experiments; $Y Z$ andYG analyzed the data; $H C$ and JX wrote the paper; MY, WS and YJ contributed reagents/materials/analysis tools; All authors read and approved the final manuscript. All authors discussed the results and commented on the manuscript.

\section{Authors' information}

Submitting author: Yimin Sun. National Engineering Research Center for Beijing Biochip Technology, Beijing 102206, China.

\section{Acknowledgements}

This work is funded by the National Key Basic Research Program Grant (2012CB720703). The authors thank all the study subjects, research staff and students who participated in this work.

\section{Author details}

${ }^{1}$ State Key Laboratory of Proteomics, Beijing Proteome Research Center, Beijing Institute of Radiation Medicine, Beijing 102206, China. ${ }^{2}$ National Engineering Research Center for Beijing Biochip Technology, Beijing 102206, China. ${ }^{3}$ CapitalBio Corporation, Beijing 102206, China. ${ }^{4}$ Department of Anatomy, The University of Hong Kong, Hong Kong, China. ${ }^{5}$ State Key Laboratory of Brain and Cognitive Sciences, The University of Hong Kong, Hong Kong, China. ${ }^{6}$ School of Humanities, The University of Hong Kong, Hong Kong, China. ${ }^{7}$ The State Key Laboratory Breeding Base-Shenzhen Key Laboratory of Chemical Biology, The Graduate School at Shenzhen, Tsinghua University, Shenzhen, China. ${ }^{8}$ Neuroimaging Laboratory, Department of Biomedical Engineering, School of Medicine, Shenzhen University, Shenzhen, China. ${ }^{9}$ Guangdong Key Laboratory of Biomedical Information Detection and Ultrasound Imaging, Shenzhen 518060, China. ${ }^{10}$ Medical Systems Biology Research Center, Department of Biomedical Engineering, Tsinghua University School of Medicine, Beijing, China.

Received: 29 September 2014 Accepted: 21 January 2015

Published online: 03 February 2015

\section{References}

1. Graham SA, Fisher SE. Decoding the genetics of speech and language. Curr Opin Neurobiol. 2013;23(1):43-51.

2. Paracchini S, Scerri T, Monaco AP. The genetic lexicon of dyslexia. In: Annual review of genomics and human genetics, vol. 8. Palo Alto: Annual Reviews; 2007. p. 57-79.

3. Gabrieli JD. Dyslexia: a new synergy between education and cognitive neuroscience. Science. 2009:325(5938):280-3.

4. Kang C, Drayna D. Genetics of speech and language disorders. Annu Rev Genomics Hum Genet. 2011:12:145-64.

5. Goulandris NK, Snowling MJ, Walker I. Is dyslexia a form of specific language impairment? A comparison of dyslexic and language impaired children as adolescents. Ann Dyslexia. 2000;50(1):103-20.

6. Malek A, Amiri S, Hekmati I, Pirzadeh J, Gholizadeh H. A comparative study on diadochokinetic skill of dyslexic, stuttering, and normal children. ISRN Pediatr. 2013;2013:165193.

7. Snowling M, Bishop DV, Stothard SE. Is preschool language impairment a risk factor for dyslexia in adolescence? J Child Psychol Psychiatry. 2000:41(5):587-600.

8. Foundas AL, Mock JR, Cindass Jr R, Corey DM. Atypical caudate anatomy in children who stutter. Percept Mot Skills. 2013;116(2):528-43.

9. Sasisekaran J. Nonword repetition and nonword reading abilities in adults who do and do not stutter. J Fluency Disord. 2013;38(3):275-89.

10. Foorman BR, Torgesen T. Critical elements of classroom and small-group instruction promote reading success in All children. Learn Disabil Res Pract. 2001;16(4):203-12.

11. Ji W, Li T, Pan Y, Tao H, Ju K, Wen Z, et al. CNTNAP2 is significantly associated with schizophrenia and major depression in the Han Chinese population. Psychiatry Res. 2013;207(3):225-8.

12. Tomblin JB, O'Brien M, Shriberg LD, Williams C, Murray J, Patil S, et al. Language features in a mother and daughter of a chromosome 7;13 translocation involving FOXP2. J Speech Lang Hear Res. 2009:52(5):1157-74.

13. Shriberg LD, Ballard KJ, Tomblin JB, Duffy JR, Odell KH, Williams CA. Speech, prosody, and voice characteristics of a mother and daughter with a 7;13 translocation affecting FOXP2. J Speech Lang Hear Res. 2006;49(3):500-25.
14. MacDermot KD, Bonora E, Sykes N, Coupe AM, Lai CS, Vernes SC, et al, Identification of FOXP2 truncation as a novel cause of developmental speech and language deficits. Am J Hum Genet. 2005;76(6):1074-80.

15. Newbury DF, Monaco AP. Genetic advances in the study of speech and language disorders. Neuron. 2010;68(2):309-20.

16. Turner SJ, Hildebrand MS, Block S, Damiano J, Fahey M, Reilly S, et al. Small intragenic deletion in FOXP2 associated with childhood apraxia of speech and dysarthria. Am J Med Genet A. 2013;161(9):2321-6.

17. Zeesman S, Nowaczyk MJ, Teshima I, Roberts W, Cardy JO, Brian J, et al. Speech and language impairment and oromotor dyspraxia due to deletion of 7q31 that involves FOXP2. Am J Med Genet A. 2006;140(5):509-14.

18. Condro MC, White SA. Distribution of language-related Cntnap2 protein in neural circuits critical for vocal learning. J Comp Neurol. 2014;522(1):169-85.

19. Rodenas-Cuadrado P, Ho J, Vernes SC. Shining a light on CNTNAP2: complex functions to complex disorders. Eur J Hum Genet. 2014;22(2):171-8.

20. Peter B, Raskind WH, Matsushita M, Lisowski M, Vu T, Berninger W, et al. Replication of CNTNAP2 association with nonword repetition and support for FOXP2 association with timed reading and motor activities in a dyslexia family sample. J Neurodev Disord. 2011;3(1):39-49.

21. Kang C, Riazuddin S, Mundorff J, Krasnewich D, Friedman P, Mullikin JC, et al. Mutations in the lysosomal enzyme-targeting pathway and persistent stuttering. N Engl J Med. 2010;362(8):677-85.

22. Kang C, Drayna D. A role for inherited metabolic deficits in persistent developmental stuttering. Mol Genet Metab. 2012;107(3):276-80.

23. Bast EJ, van Amstel HK, Franken MC. [Stuttering: effects of genes and early treatment]. Ned Tijdschr Geneeskd. 2011;155(42):A3514.

24. Drayna D, Kang C. Genetic approaches to understanding the causes of stuttering. J Neurodev Disord. 2011;3(4):374-80.

25. Leroy JG, Sillence D, Wood T, Barnes J, Lebel RR, Friez MJ, et al. A novel intermediate mucolipidosis II/Illalphabeta caused by GNPTAB mutation in the cytosolic N-terminal domain. Eur J Hum Genet. 2014;22(5):594-601.

26. Cathey SS, Leroy JG, Wood T, Eaves K, Simensen RJ, Kudo M, et al. Phenotype and genotype in mucolipidoses II and III alpha/beta: a study of 61 probands. J Med Genet. 2010;47(1):38-48

27. Kollmann K, Pohl S, Marschner K, Encarnacao M, Sakwa I, Tiede S, et al. Mannose phosphorylation in health and disease. Eur J Cell Biol. 2010;89 (1):117-23.

28. Page T, Zhao KW, Tao L, Miller AL. Purification and characterization of human lymphoblast $\mathrm{N}$-acetylglucosamine-1-phosphodiester alpha-Nacetylglucosaminidase. Glycobiology. 1996;6(6):619-26.

29. Lee WS, Kang C, Drayna D, Kornfeld S. Analysis of mannose 6-phosphate uncovering enzyme mutations associated with persistent stuttering. J Biol Chem. 2011;286(46):39786-93.

30. Tan $\mathrm{LH}, \mathrm{Xu} \mathrm{M}$, Chang $\mathrm{CQ}$, Siok WT. China's language input system in the digital age affects children's reading development. Proc Natl Acad Sci U S A. 2013;110(3):1119-23.

31. de Bakker PIW, Yelensky R, Pe'er I, Gabriel SB, Daly MJ, Altshuler D. Efficiency and power in genetic association studies. Nat Genet. 2005:37(11):1217-23.

32. Purcell S, Neale B, Todd-Brown K, Thomas L, Ferreira MA, Bender D, et al. PLINK: a tool set for whole-genome association and population-based linkage analyses. Am J Hum Genet. 2007;81(3):559-75.

33. Barrett JC, Fry B, Maller J, Daly MJ. Haploview: analysis and visualization of LD and haplotype maps. Bioinformatics. 2005;21(2):263-5.

34. Barrett JC. Haploview: visualization and analysis of SNP genotype data. Cold Spring Harb Proto. 2009;2009(10):pdb.ip71. 